BRAGA, Ruy. 2003. A nostalgia do fordismo. Modernização e crise na teoria da sociedade salarial.

São Paulo : Xamã.

\title{
UMA CRÍTICA À ECONOMIA POLÍTICA DA TERCEIRA VIA
}

\author{
Alvaro Bianchi
}

Nesta resenha, pretendo mostrar como A nostalgia do fordismo, de Ruy Braga, constitui-se em uma obra madura capaz de inspirar a ação política e teórica dos sujeitos comprometidos com a transformação do presente. Para tal considero necessário cotejar essa obra com A restauração do capital, livro publicado pelo mesmo autor em 1997. Braga é professor de Sociologia da Universidade de São Paulo (USP) e secretário de redação da revista Outubro. Como seu amigo e colaborador há mais de seis anos, discuti com ele muitas das questões que serão aqui tratadas, preservando a mútua independência e a autonomia crítica. Considerando essas questões relevantes, nada melhor do que as tornar públicas e estimular um debate sobre os caminhos teóricos abertos pelo autor.

Entrei em contato com Braga por meio da revisão de sua primeira obra solo, A restauração do capital. $\mathrm{O}$ livro era extremamente ambicioso, mas não é essa uma de suas virtudes. Dividido em duas partes, desconstruía, na primeira, as teses sobre a abolição do trabalho e os argumentos do pós-fordismo, por meio da crítica de Habermas, Gorz e Kurz, Piore, Sabel, Aglietta e Coriat. A seguir, na segunda parte, utilizando os conceitos de crise orgânica e revolução passiva de Antônio Gramsci, explicitava as estratégias de passivação do Estado e das forças produtivas: "O neoliberalismo corresponderia ao processo de passivização [sic] no nível do aparelho e da formas estruturais da intervenção estatal, assim como a reestruturação produtiva em curso encarnaria esse mesmo movimento no âmbito do sistema das forças produtivas" (BRAGA, 1997, p. 213).

A força da tese não se encontra no enfoque dado ao neoliberalismo, muito embora o tratamento a partir das categorias gramscianas seja um exercício teórico levado a cabo com competência. Seu vigor está na politização do debate sobre a reestruturação produtiva. A crítica ao pós-fordismo já havia, é verdade, enquadrado as transformações no universo produtivo no conjunto de mudanças econômicas que permitiram uma recomposição da taxa de lucro e da acumulação do capital (cf. HARVEY, 1992). Faltava ainda - e essa é a contribuição de A restauração do capital - enfatizar as dimensões políticas dessas transformações: a reestruturação produtiva como revolução passiva capaz de fragmentar e imobilizar a classe operária. A tese, desenvolvendo-se como análise da relação de forças sociais, rompia com o determinismo tecnológico predominante no debate e apresentava-se como crítica prática.

Duas resenhas àquela obra merecem comentários. Em ambas são ressaltadas a capacidade analítica do autor e sua ruptura com as concepções dominantes. Mas elas também se destacam por indicar aquilo que seriam os pontos fracos da obra. A primeira delas, de Jesus Ranieri (1997), publicada na Revista de Sociologia e Política, destaca as imprecisões conceituais de Braga e a indefinição de seus conceitos de forças produtivas e luta de classes, em primeiro lugar: "A dificuldade maior está no fato de que a partir de um conteúdo suposta e abstratamente dado retira a substância verdadeiramente dinâmica do real, na medida em que se parte de um modelo pré-estabelecido (mas que só existe na cabeça do autor) que aglutina no seu interior diagnósticos e posições visceralmente distintos: é a realidade que cabe no modelo (de forças produtivas e luta de classes) e não o modelo que corresponde à realidade (das forças produtivas e da luta de classes)" (idem, p. 214).

Na segunda delas, publicada na revista Crítica Marxista, Hector Benoit (1997), colocando-se no mesmo campo político-teórico de Braga, aponta quatro problemas que, segundo ele, mereceriam reparos: o primeiro é a ausência do tema da crise de direção da classe trabalhadora como elemento constitutivo da crise orgânica; o segundo é a ausência de um tratamento mais aprofundado do Marx de $O$ capital, notadamente da seção IV; o terceiro é a utilização acrítica da leitura de Eric Hobsbawm sobre o século XX e o quarto é a presença de um jargão pós-gramsciano, que Benoit identifica nas citações de André Tosel e que retirariam força e clareza do argumento. 
A partir dessas considerações de Ranieri e Benoit, apontarei quais são, de meu ponto de vista, as regiões problemáticas de A restauração do capital em que se pode identificar uma tensão própria de uma reflexão em construção ao invés de uma formulação acabada. A primeira delas está localizada na chamada "problemática das forças produtivas". Ranieri intui isso, mas não consegue extrair daí as conclusões adequadas; sua afirmação de que o conceito de forças produtivas de Braga estaria explícito apenas "em sua cabeça" é injusta. A existência de um subcapítulo intitulado "O estatuto do conceito de forças produtivas em Marx" atesta a leitura superficial de Ranieri. O modelo não existe apenas "na cabeça do autor"; ele está amparado em uma importante tradição do marxismo, explicitada e desenvolvida por Braga.

A "problemática das forças produtivas" em A restauração do capital não é tributária do pensamento pósgramsciano - denunciado por Benoit - e sim do marxismo estruturalista. O estatuto do conceito de forças produtivas é apresentado a partir dos comentários de Ettiene Balibar (1980) e A. D. Magaline (1977). É apoiando-se nesses autores que Braga critica as concepções que vêem as forças produtivas como "elementos isolados, passíveis de enumeração e substituição conforme o estágio de seu desenvolvimento" (BRAGA, 1997, p. 71). Tais concepções partiriam do suposto de que as forças produtivas seriam classificáveis em subsistemas remetidos ao trabalho ou aos meios objetivos. Segundo Braga, a crítica a essas concepções exige a recusa ao princípio da "teorização em si da natureza das forças produtivas" (idem, p. 72). Talvez, ao ler essa afirmação, Ranieri tenha interpretado que o autor é contrário a toda teorização das forças produtivas, quando o que ele descarta é o tratamento das forças produtivas como coisas. Afirma Braga: "A demonstração da tese de que, em Marx, as forças produtivas são, na verdade, relações de apropriação do real só é possível a partir de uma análise centrada nos capítulos de $O$ capital destinados aos métodos de formação da mais-valia relativa [...]. Em nosso entendimento, a verificação de tal tese foi levada a bom termo por Balibar e Magaline" (idem, p. 71; sem grifos no original).

Benoit censura Braga por não utilizar $O$ capital de maneira adequada - e tem razão. Apesar da promessa, o tratamento da obra de Marx em A restauração do capital é, na verdade bastante reduzido, limitando-se ao "Prefácio" de 1859 à Contribuição à crítica da economia política, e, mesmo assim, só é citado para apontar, seguindo Magaline, que, no "Prefácio", Marx “reconduz o conjunto do movimento histórico ao desenvolvimento das forças produtivas" (idem, p. 72), reproduzindo um mecanicismo já presente em A ideologia alemã. Seria apenas em $O$ capital, quando Marx introduz os conceitos de relações de produção e reprodução, que essa perspectiva seria superada.

A definição das forças produtivas como "relações de apropriação do real" pressupõe a subsunção do conceito de forças produtivas ao de relações de produção. Essa idéia, que não está explícita em Balibar, é desenvolvida por Magaline (1977, p. 21-70). Braga acompanha-o placidamente. Subjacente a essa diluição da materialidade das forças produtivas e à emancipação das relações de produção de todo constrangimento material está uma concepção voluntarista do devir histórico, em que a luta de classes afirmar-se-ia livremente, permitindo aos homens e mulheres fazer a história nas condições por eles definidas. A contraditoriedade que se estabelece na história real, na unidade entre o desenvolvimento das forças produtivas e as relações de produção, afirmada incansavelmente por Marx, sucumbe perante uma leitura seletiva da seção IV de O capital.

Dizia-se que essa concepção compõe uma das regiões problemáticas de $A$ restauração do capital porque seu voluntarismo subjacente permite, ao autor, deduzir a política reformista de uma certa concepção de forças produtivas, como se o determinismo produzisse a passividade. Os limites teóricos dessa formulação estruturalista aparecem quando o autor passa aos conceitos de crise orgânica e revolução passiva. Fundada na dialética entre estrutura e práxis, a rica tradição gramsciana solidamente apresentada por Braga fica pouco à vontade com os esquemas de Balibar e, principalmente, Magaline.

Outra região problemática aparecerá na segunda parte do livro. Nela Braga desenvolve uma concepção claramente campista da política no período posterior à II Guerra Mundial, tributária, em grande parte, de sua apropriação acrítica de uma leitura pós-stalinista, notadamente de Eric Hobsbawm (1995) e, sabe-se lá por que razão, de Nelson Levy (1980). De um lado o bloco capitalista, de outro o "coletivista de Estado". A contradição entre esses dois blocos "sobredeterminaria" as contradições, "envolvendo classes sociais, estruturas imperialistas, Estados centrais e subalternizados” (BRAGA, 1997, p. 158). Assim, os movimentos nacionalistas na Ásia e África que alimentaram o processo de descolonização foram, segundo Braga, sobredeterminados pela existência da União Soviética: “Os anos após 1945 foram de consolidação desse exemplo, dado pela União Soviética, de crescimento econômico acelerado e alheio às estruturas imperialistas de poder do grande capital financeiro multinacional. Daí um dos fatores responsáveis pelo crescente apelo comunista no Terceiro 
Mundo" (idem, p. 172).

Se Braga não discute a crise de direção revolucionária, como Benoit quer, é porque em sua visão campista não havia lugar para tal. A apropriação dessa visão, típica do estruturalismo já apontado, é problemática e manifesta-se como uma questão não resolvida até então pelo autor. Três são as razões que permitem afirmar isso. Primeiro, há uma tensão clara entre a definição do momento atual como o de uma crise orgânica e as conclusões a que essa visão campista poderia chegar a partir do colapso da União Soviética (vitória do capitalismo, hegemonia estadunidense etc.). Segundo, o conceito de "coletivismo de Estado" é, para o autor, um não-conceito, ou seja, uma forma de fugir do debate sobre a natureza social da União Soviética, o que revela sua dificuldade de amparar teoricamente sua tese campista. Em terceiro lugar, ao evitar cuidadosamente as armadilhas do progressivismo inerentes ao campismo, Braga coloca-se em um campo que é o da política revolucionária.

Afirmava, no início da resenha, que $A$ nostalgia do fordismo é uma obra madura. Se assim penso é porque, nela, Braga desenvolve muitos de seus insights de $A$ restauração do capital, ao mesmo tempo em que resolve, de maneira satisfatória, aquelas duas regiões problemáticas acima apontadas. Os objetivos do novo livro de Ruy Braga são muito mais modestos do que aqueles que haviam motivado o primeiro. Trata-se de uma análise crítica da chamada escola regulacionista, com ênfase particular em sua corrente parisiense (Aglietta, Boyer e Coriat, principalmente). Assim, o novo livro expande temas tratados nos capítulos 2 e 5 de $A$ restauração do capital. Mas o projeto é teoricamente mais ambicioso e aqui isto constitui uma das principais virtudes do livro. É por meio desse diálogo crítico que Braga constrói uma ampla crítica à economia política do reformismo, afirmando, ao mesmo tempo, caminhos através dos quais é possível revitalizar o marxismo no início do século XXI.

A escolha do tema pode parecer estranha ao ambiente intelectual brasileiro. A principal obra da escola regulacionista, o trabalho seminal de Michael Aglietta, Régulation et crises du capitalisme (1997), nem ao menos encontra-se traduzida para o português e, dos demais expoentes da corrente parisiense, tem-se apenas A teoria da regulação: uma análise crítica, de Robert Boyer (1990), e Pensar pelo avesso, de Benjamin Coriat (1994), além de duas obras de Alain Lipietz: Miragens e milagres (1988) e Audácia (1991). Mas Braga não escolhe o adversário. É o adversário que o escolhe. Fiel à máxima de Gramsci - "uma ciência nova alcança a prova de sua eficiência e vitalidade fecunda quando demonstra saber afrontar os grandes campeões de tendências opostas" (GRAMSCI, 1977, p. 1423) - o autor de A nostalgia do fordismo mede forças com a matriz da economia política do reformismo. E o faz com paciência e competência admiráveis. Abordando o conjunto da obra da corrente parisiense da regulação, Braga evita a armadilha dos textos fáceis e acessíveis e reconstrói de maneira minuciosa o intrincado processo de desenvolvimento teórico que levou uma corrente de inspiração inicialmente althusseriana à apologia da concertação social.

Com Aglietta, a escola regulacionista debruçou-se sobre a crise econômica que se configurava a partir do início dos anos 1970 e manifestava-se no choque do petróleo de 1973 e na persistente inflação do período. A conjuntura econômica de então era interpretada como "uma crise da regulação salarial localizada, fundamentalmente, no âmbito das contradições produzida pela organização do processo de trabalho" (BRAGA, 2003, p. 37). Ou seja, a crise do capital foi apresentada como crise do fordismo nas suas múltiplas dimensões: como regime de acumulação, como modo de regulação e como modo de desenvolvimento. Tomando como ponto de partida o fordismo plenamente constituído do pós-II Guerra Mundial, a escola regulacionista suprimia o momento da luta. A conjuntura crítica dos anos 1930 nos Estados Unidos, bem como os anos finais da II Guerra na Europa, desapareciam. Em seu lugar, na cosmogonia regulacionista, restava o momento da passivização da classe operária estadunidense e européia. "No princípio era a luz".

Metodologicamente, o artifício replica a historiografia de Benedetto Croce e sua história da Europa que começava em 1815 e não em 1789, 1830 ou 18481. Suprimido o momento da luta, o fordismo aparece não como parte e resultado da luta de classes no terreno da produção e sim como o produto de uma institucionalização de relações econômicas capaz de impor "coerções ao capital correlativamente à integração dos assalariados"

\footnotetext{
1 "Croce inicia suas narrações a partir de 1815 e 1871, ou seja, que prescinde o momento da luta, o momento no qual se elaboram e agrupam e alinham as forças em contraste, o momento em que um sistema ético-político se dissolve e outro se elabora a ferro e fogo, no qual um sistema de relações sociais se desintegra e decai e outro sistema surge e se afirma" (GRAMSCI, 1977, p. 1227).
} 
(AGLIETTA, 1997, p. 427). Organizando a sociedade e regulando o conflito capital-trabalho, o Estado fordista mostrar-se-ia capaz de preservar os pré-requisitos da acumulação de capital e, ao mesmo tempo, expandir a relação salarial. Para Aglietta, o fordismo "representa um novo estágio da regulação do capitalismo, o do regime de acumulação intensiva, em que a classe capitalista busca gerir a reprodução global da força de trabalho assalariada por meio da íntima articulação das relações de produção e mercantis mediante as quais os trabalhadores assalariados adquirem seus meios de consumo" (idem, p. 93-94). A reconstrução histórica regulacionista, ao enfatizar o momento da restauração do capital, coloca-se a si própria como ideologia dessa revolução passiva.

Ao generalizar a forma salarial, como custo para as empresas e meio de consumo para os assalariados, criavam-se as condições para um ciclo virtuoso responsável pelos "trinta gloriosos", o período mais espetacular de expansão do capitalismo no século XX. Essa articulação entre norma social de consumo e forma salarial já anunciava, para os regulacionistas, sua crise: a elevação do custo social de reprodução da força de trabalho limitaria a taxa de mais-valia, obstaculizando a acumulação do capital. O argumento é próximo daquele que ficou conhecido como profits squeeze desenvolvido dentre outros por Philip Armstrong, Andrew Glyn e John Harrison (1984, cap. 11). Às mediações institucionais e, principalmente, ao Estado caberia encontrar aquele ponto em que os salários, garantindo padrões de consumo elevados, não comprometeriam a virtuosidade do ciclo de acumulação.

Aparece aqui aquela que é a contradição fundamental para os regulacionistas, a que se estabelece entre os progressos da produtividade e a socialização dos modos de vida. Aparece, também, aquela que seria a possibilidade de resolução dessa contradição, a renovação da ação estatal e a constituição de uma forma institucional capaz de reconstruir o consenso perdido. Compatibilizar as demandas do capital com as exigências do trabalho por meio da mediação estatal: esse é o programa da escola regulacionista. Daí o fascínio que demonstraram nos anos 1990 pelo modelo japonês de trabalho e organização. "Apoderar-se da eficácia que traz o método japonês para abrir o contrato e o compromisso", essa é a alternativa para Benjamin Coriat (1994, p. 174).

Não é senão in nuce que esse programa aparece em Régulation et crises du capitalisme. A tese é nuançada, com propriedade, por Michel Husson, em seu prefácio ao livro de Braga: "Parece-me que a trajetória da escola é caracterizada por uma alteração progressiva, ou mesmo uma ruptura, e que seu ponto de chegada não estava totalmente programado no princípio" (HUSSON, 2003, p. 10). Detida a análise no texto original de Aglietta, o argumento de Braga ficaria, assim, carregado de um viés fortemente teleológico. Esse viés é evitado pela reconstrução criteriosa da trajetória regulacionista no interior do aparelho de Estado francês, acompanhando, ao mesmo tempo, seu desenvolvimento teórico. O autor de $A$ nostalgia do fordismo torna-se capaz disso na medida em que resolve as duas regiões problemáticas presentes em $A$ restauração do capital.

Em primeiro lugar, Braga abandona a concepção estruturalista das forças produtivas e substitui-a por uma concepção dialética da articulação entre forças produtivas e relações de produção. A "ruptura epistemológica" é notável. Magaline, outrora onipresente, desaparece da bibliografia e as menções a Balibar privilegiam sua nova abordagem, inspirada em Gramsci e Walter Benjamin e plasmada em La philosophie de Marx (1995), ao invés da ortodoxia estruturalista de Lire Le Capital. A ruptura não é só notável; ela é necessária para a crítica. "Filhos rebeldes de Althusser", os regulacionistas partilhavam, também, a idéia de "forças produtivas como relação de apropriação do real". Braga identifica essa origem, ao mesmo tempo em que mostra que, mesmo afastando-se do marxismo, a escola regulacionista não rompe com os supostos dessa definição. É na crítica à teoria da regulação que o autor de $A$ nostalgia do fordismo construirá sua própria concepção. A luta de classes ocupa nela um lugar central, mas a relação de forças gerada nessa luta não deixa de ter como pressuposto a materialidade das classes sociais, a "relação de forças objetivas", como diria Gramsci, sobre as quais ela se constitui. É portanto na análise da unidade dialética entre forças produtivas e relações de produção e na constituição dessa unidade em um tempo fraturado que Braga inscreve sua obra.

O novo "estatuto do conceito de forças produtivas" e portanto de sua relação com as relações de produção não está, entretanto, plenamente desenvolvido no texto. A tensão original vez por outra reaparecerá novamente. Mas ela não é nem assumida nem reconhecida por Braga. A solução dada a essa tensão não me parece das melhores: abusando das metáforas e de uma linguagem elíptica o autor evita o desafio. Parece preferir, conscientemente, uma conceituação menos precisa mas ao mesmo tempo mais plástica que lhe permita captar a materialidade das classes e de suas lutas. É uma solução possível, mas ela própria merecia ser teorizada. 
Para os objetivos do autor essa conceituação plástica revela-se eficaz e condu-lo a uma análise sociológica não reducionista da escola da regulação. Destacando sua presença no interior dos órgãos de planejamento do Estado francês, Braga identifica as bases materiais para o fetiche do Estado salarial. Como os filósofos criticados por Marx, que acreditavam no poder de suas idéias constituírem o real, os regulacionistas confiam na capacidade de os gestores estatais produzirem a nova articulação entre progresso e direitos. Com a ascensão de Mitterrand à presidência da França, "a Teoria da Regulação transforma-se em técnica da regulação" (BRAGA, 2003, p. 63). É como técnica da regulação que essa teoria aparece como o programa econômico da terceira via socialdemocrata. Com a mediação de um Estado ambivalente seria possível costurar a aliança entre a fração modernizante da burguesia francesa e as organizações sindicais da classe trabalhadora, particularmente a Confédération Française Démocratique du Travail (CFDT). Tal aliança não poderia mais resolver-se no Programa Comum que havia unificado o Partido Socialista e o Partido Comunista Francês nas eleições de 1981. Em meio à recessão do início dos anos 1980, tal programa foi rapidamente abandonado. Em seu lugar, consolidou-se a "alternativa européia".

Foi nessa situação que a escola regulacionista encontrou-se no começo da década de 1980. Seu desenvolvimento posterior, conforme reconstruído por Braga na segunda parte de seu livro, levou-a cada vez mais longe do marxismo e mais perto de um Estado demiurgo. Acossada pela guinada neoliberal, a escola regulacionista afinou seu discurso e seu programa. O neoliberalismo, com seu paradigma liberal-produtivista, não se constituiria em uma alternativa à crise na medida em que ele aumentaria, ao invés de resolver, a contradição existente entre os progressos da produtividade e a socialização dos modos de vida. "Um grande compromisso a ser negociado com os cidadãos residentes na Europa" permitiria construir a alternativa a esse paradigma neoliberal (LIPIETZ, 1991, p. 166).

Mantida a visão campista de sua primeira obra, dificilmente o autor de $A$ nostalgia do fordismo seria capaz de perceber a novidade da "alternativa européia" e da trajetória dos regulacionistas nas décadas que se seguiram ao trabalho fundador de Aglietta. Sua ruptura com essa concepção solucionará a segunda região problemática de A restauração do capital e permitir-lhe-á criticar o reducionismo de tais teorias. Ao circunscrever a política às escolhas entre opções antitéticas (o bem e o mal, o progresso e a decadência, a direita e a esquerda etc.), elas ocultam o campo real das lutas, aquele em que classes, frações e suas formas institucionais medem forças e constroem seus projetos. A escolha do mal menor é sempre a opção pela reprodução do presente (BRAGA, 2003, p. 161-162).

Para a economia política da terceira via, a opção é certa: o progresso da técnica, das formas institucionais e da sociedade salarial. Vencer a crise é restaurar a norma e, com isso, garantir as condições para a reprodução ampliada do capital. Para Braga, a crise dissolve certezas, explode o tempo histórico, revela os conflitos latentes, traz para o palco os sujeitos sociais. Ao invés da adequação às regras, seu conceito de crise remeteo para as transformações econômicas e políticas e para os conflitos sociais reais, para uma história que "não pronunciou a última palavra" (idem, p. 216).

Álvaro Bianchi (albianchi@terra.com.br)é Doutor em Ciências Sociais pela Universidade Estadual de Campinas (UNICAMP) e Professor do Departamento de Ciência Política da mesma universidade.

\section{REFERÊNCIAS BIBLIOGRÁFICAS}

AGLIETTA, M. 1997. Régulation et crises du capitalisme. Paris : O. Jacob.

ARMSTRONG, P., GLYN, A. \& HARRISON, J. 1984. Capitalism Since World War II. London : Fontana.

BALIBAR, E. 1980. Sobre os conceitos fundamentais do materialismo histórico. In : ALTHUSSER, Louis (org.). Ler O Capital. Rio de Janeiro : Zahar.

BALIBAR, G. 1995. A filosofia de Marx. Rio de Janeiro : Zahar.

BENOIT, H. 1997. Resenha. Crítica Marxista, São Paulo, n. 5, p. 168-171. Resenha de BRAGA, R. A restauração do capital. Um estudo sobre a crise contemporânea. São Paulo : Xamã.

BOYER, R. 1990. A teoria da regulação : uma análise crítica. São Paulo : Nobel. 
BRAGA, R. 1997. A restauração do capital. Um estudo sobre a crise contemporânea. São Paulo : Xamã.

CORIAT, B. 1994. Pensar pelo avesso. Rio de Janeiro : Revan.

GRASMCI, A. 1997. Quaderni del carcere. Turim : G. Einaudi.

HARVEY, D. 1992. Condição pós-moderna. São Paulo : Loyola.

HOBSBAWM, E. 1995. Era dos extremos. O breve século XX: 1914-1991. São Paulo : Cia. das Letras.

HUSSON, M. 2003. Prefácio. In : BRAGA, R. A nostalgia do fordismo. Regulação e crise na teoria da sociedade salarial. São Paulo : Xamã.

LEVY, N. 1980. A crise do imperialismo e a revolução. São Paulo : Brasil Debates.

LIPIETZ, A. 1988. Miragens e milagres. Problemas da industrialização no Terceiro Mundo. São Paulo : Nobel. 1991. Audácia. Uma alternativa para o século XXI. São Paulo : Novel.

MAGALINE, A. D. 1977. Luta de classes e desvalorização do capital. Lisboa : Moraes.

RANIERI, J. 1997. A crise do capitalismo hoje. Revista de Sociologia e Política, Curitiba, n. 9, p. 213-215, nov. Resenha de BRAGA, R. A restauração do capital. Um estudo sobre a crise contemporânea. São Paulo : Xamã. 